\section{Using lithium isotopes to quantitatively extract the silicate weathering signal registered in the Changjiang (Yangtze) estuarine sediments}

FANG CAO $^{1}$, SHOU-YE YANG ${ }^{1}$, CHENG-FAN YANG ${ }^{1}$, YU-LONG GUO ${ }^{1}$, LEI BI ${ }^{1,2}$ AND YU-ZE LI ${ }^{3}$

${ }^{1}$ Tongji University

${ }^{2}$ Polar Research Institute of China Polar Research Institute of China

${ }^{3}$ Fudan University

Presenting Author: caofang@tongji.edu.cn

As the key link connecting the earth's spheres, continental weathering plays an important role in regulating the global biogeochemical cycle and long-term climate change. Siliciclastic sediments derived from large river basins can record continental weathering and erosion signals, and are thus widely used to investigate weathering processes. However, grain size, hydrodynamic sorting and sedimentary recycling complicate the interpretation of sediment weathering proxies. This study presents the elemental and lithium isotopic compositions of estuarine seafloor sediments and suspended particulate matters (SPM) in the Changjiang (Yangtze River) Estuary. The $\delta^{7} \mathrm{Li}$ values of estuarine sediments vary from $-0.2 \%$ to $2.0 \%$, and the SPM samples have lower $\delta^{7} \mathrm{Li}$, ranging from $-1.5 \%$ to $-0.3 \%$. The $\delta^{7} \mathrm{Li}$ values decrease with increasing $\mathrm{Al} / \mathrm{Si}$ ratios (i.e., grain size proxy), reflecting that hydrodynamic sorting can affect the mixing proportions of un-weathered igneous, sedimentary rock fragments and modern weathering products in sediments studied. Following the method suggested by Dellinger et al. ${ }^{[1]}$, the proportions of these end-members were quantitatively calculated. Overall, the samples in the Changjiang Estuary are mainly eroded from un-weathered rock fragments $(>60 \%)$, while the modern weathering products occupy less than $40 \%$ (Fig. 1). The fine-grained SPM contain more shale components $(\sim 52 \%$ to $66 \%$ ), and modern weathering products account for $\sim 21 \%-40 \%$. Comparatively, the coarse-grained surface sediments contain more un-weathered igneous rock fragments (63\% to $84 \%$ ) and lesser modern weathering products (only $4 \%$ to $18 \%$ ). The comparison of $\delta^{7} \mathrm{Li}$ values with the weathering proxy (CIA) suggests that sediment weathering intensity decreases with increasing proportion of un-weathered igneous rock fragments. In addition, the occurrence of inherited weathering products (i.e., shale in Fig. 2) in modern sediments makes it a challenge to simply use CIA and $\delta^{7} \mathrm{Li}$ as indicators of weathering intensity. This study confirms that fine-grained particles are more suitable for tracing contemporary weathering process, albeit with the influence of sedimentary recycling. Lithium isotopes combining with the mass balance model can quantitatively constrain the continental weathering processes in large river basins.

[1] Dellinger et al. 2014. Lithium isotopes in large rivers reveal the cannibalistic nature of modern continental weathering and erosion. Earth Planet Sc Lett, 401: 359-372
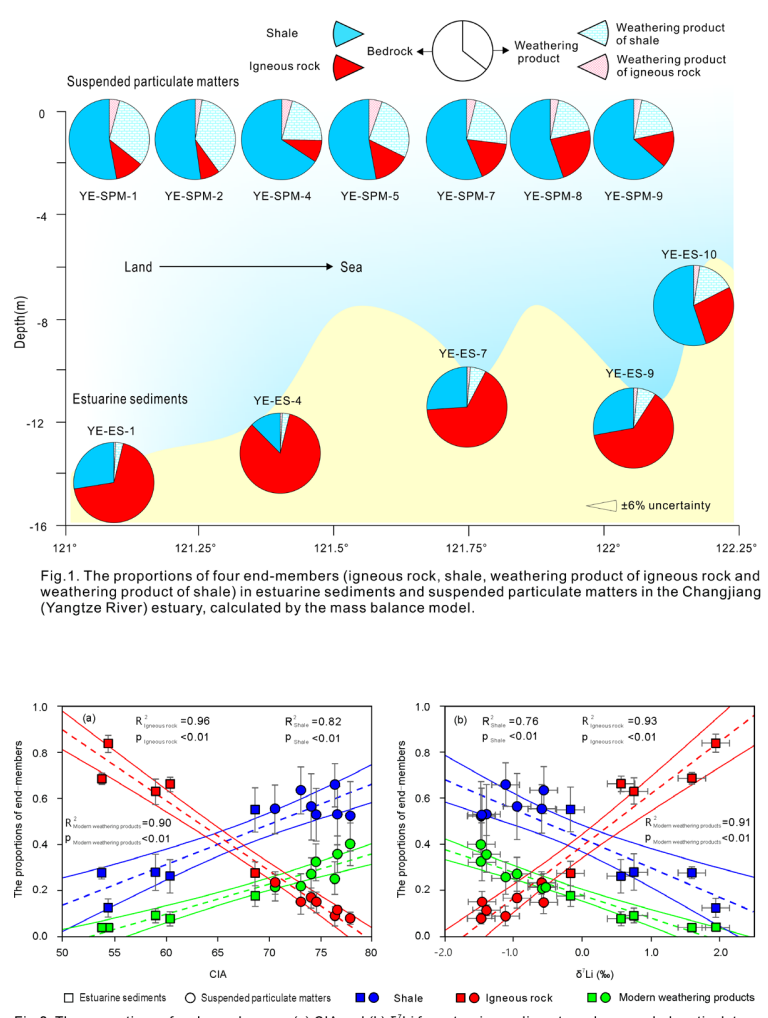

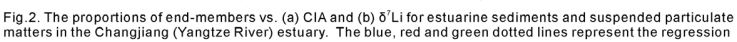

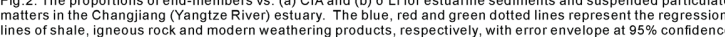

